\title{
PROPHYLACTIC USE OF PROGESTERONE VAGINAL SUPPOSITORY IN PREVENTION OF RECURRENT PRETERM LABOR
}

\author{
By \\ Mohamed M. Lotfy, Ahmed S. Amer and Adel A. El-Boghdady \\ Department of Obstetrics and Gynecology, Faculty of Medicine, Al-Azhar University \\ Corresponding Author: Mohamed Mamdouh Lotfy Ali \\ E-mail: mam64156@gmail.com
}

\begin{abstract}
Background: Prematurity is the leading cause of neonatal morbidity and mortality. Although perinatal care advanced in the last few decades, preterm labor did not decrease but even is increasing and creating a great social and economic problem.
\end{abstract}

Objective: To test the effectiveness of progesterone vaginal suppository in prevention of preterm labor in patients with previous history of preterm labor.

Patients and Methods: This was a randomized, prospective, single blind study after approval of the medical ethical committee at Al-Azhar university Hospitals, Department of Obstetrics and Gynecology, and after patients giving written consents, during the period from February 2020 to October 2020 . We enrolled 168 women for the study at high risk for preterm labor who were randomly divided into two groups (progesterone group and placebo group). Two hundred mg of vaginal progesterone pessary or placebo were used by the patient from 24 to 36 weeks of gestation. Uterine contractions were recorded by external tocodynamometer every other week from 28 to 36 weeks of gestations.

Results: There was a statistically significant reduction in the incidence of preterm delivery between the two groups from $38.5 \%$ in placebo group, compared with $21 \%$ in progesterone group. There was also a statistically significant reduction in the incidence of early preterm delivery $(<34$ week) between the two groups from $21.2 \%$ in placebo group, compared with $5.7 \%$ in progesterone group. There was a significant prolongation of the mean gestational age at delivery from $36.36 \pm 2.83$ weeks in placebo group compared to $37.57 \pm 1.72$ weeks in progesterone group. There was no statistically significant difference in the average gestational age for those who had preterm birth between both groups. There were fewer women in progesterone group who reported symptoms of preterm labor of $52.4 \%$, compared with $75 \%$ in placebo group. There was a significant more frequent uterine contraction in placebo group of $48.1 \%$ compared to progesterone group of $24.8 \%$.

Conclusion: Prophylactic vaginal progesterone reduces the rate of preterm labor, prolongs gestational age at delivery, reduces the frequency of uterine contractions, and improves the symptoms of preterm labor in women at high risk of preterm labor.

Key words: Prophylactic, progesterone, vaginal suppository, recurrent preterm labor.

\section{INTRODUCTION}

Preterm labor is defined as the presence of uterine contractions of sufficient frequency and intensity to effect progressive effacement and dilation of the cervix prior to term gestation (before completing 37wks of gestation) (ACOG Practice Bulletin, 2018).

In Europe and many developed countries, the preterm birth rate is 
generally $5-9 \%$, and in the USA has even risen to $12-13 \%$ in the last decades (Delnord et al., 2015).

The obstetric events that precede preterm labor are spontaneous preterm labor constitutes $40-45 \%$ of all preterm labors, $25-30 \%$ of preterm labors occur after premature rupture of membranes. The remainders $30-35 \%$ of preterm labors are induced for obstetrical reasons. Obstetricians may have to deliver the baby preterm because of a deteriorating intrauterine environment, i.e. infection, intrauterine growth retardation, or significant endangerment of the maternal health, i.e. preeclampsia, cancer (Iams and Berghella, 2010).

By gestational age, 5\% of preterm labor occur at less than 28 weeks (extreme prematurity), $15 \%$ at $28-31$ weeks (severe prematurity), $20 \%$ at $32-33$ weeks (moderate prematurity), and $60-70 \%$ at 34-36 weeks (near term) (Wagura, 2014).

The early detection of pregnant women at high risk for preterm labor could be the best way to prevent preterm labor. Thereby, bed rest, cervical cerclage, bacterial vaginosis treatment, and prophylactic use of progesterone could be one of the managements in this high-risk population (Rundell and Panchal, 2017).

A study has shown that frequency and intensity of uterine contractions are increased before the onset of preterm labor than term labor (Suman and Luther, 2020).

Progesterone is useful in allowing pregnancy to reach its physiologic term. In animal studies, medroxyprogesterone treatment prevented labor and possessed anti-inflammatory activity in vivo.
Moreover, progesterone antagonists given at term increase the rate of spontaneous labor (Micks et al., 2015).

Progesterone, at sufficient levels in the myometrium, blocks the oxytocin effect of prostaglandin $\quad F 2 \alpha$ and $\alpha$-adrenergic stimulation and, therefore, increases the $\alpha$ adrenergic tocolytic response (Kota et al., 2013).

The present work aimed to test the effectiveness of progesterone suppository in prevention of preterm labo in patients with previous history of preterm labor.

\section{PATIENTS AND METHODS}

The primary outcome was the occurrence of delivery before 36 weeks gestation.

The secondery outcome was reduction of the rate of preterm labor, and prolongation of gestational age at delivery, improvement of the symptoms of preterm labor.

This randomized, single blind, prospective clinical trial study after approval of medical ethical committee at Al-Azhar university Hospitals. All patients gave written informed consent.

The study was performed at Al-Azhar university Hospitals (Al-Hussein and Sayed Galal hospitals) during the period from February 2020 to October 2020. One hundred sixty eight (168) pregnant women who have history of previous preterm labor were selected in this study and randomly arranged in two groups (progesterone group and placebo group).

\section{Inclusion criteria:}

Singleton pregnancy, pregnancy of less than 36 weeks of gestation and past 
history of one or more spontaneous preterm labor.

\section{Exclusion criteria:}

1. Multifetal pregnancy.

2. History of ante partum PROM.

3. Cervical Incompetence or current cervical cerclage.

4. Known fetal anomaly.

5. Hypertension requiring medications.

6. Progesterone or Heparin treatment in current pregnancy.

7. History of thrombo-embolic disorders.

8. Known allergy to progesterone.

9. Known liver disease.

10. Established preterm labor.

\section{All women were subjected to:}

\section{A. At the first antenatal visit:}

1. History taking: Full personal, obstetric, menstrual and medical history was taken. Data were collected in a special form for each patient.

2. Estimation of gestational age: Estimation on the basis of the last menstrual period and ultrasonography up to12 weeks or by two concordant scans between 12 and 24 weeks.

3. Prophylactic medical treatment: All pregnant women in the study received prophylactic medical treatment for bacterial vaginosis and Chlamydial infection in the form of Azithromycin tablets $500 \mathrm{mg}$. orally once daily for 3 days and Metronidazole tablets 250 mg. three times per day for 7 days. Medication was given just before starting progesterone therapy.
4. All women received progesterone pessaries containing $200 \mathrm{mg}$ of natural progesterone per pessary (Prontogest) or placebo. It was used by the patient as one pessary per vaginum at bed time. Women were showed how to use the pessary. Medication was started at 24 weeks and stopped at the end of 36 weeks.

5. All women were advised about the benefit of the drug used and a written approval of the study was taken from each woman. A schedule of next visits was given to each woman.

\section{B. At the follow up visits:}

All pregnant women were submitted to uterine contraction monitoring by an external tocodynamomerer every other week for 60 minutes by an external monitor from 28 to 36 weeks of gestation while women in left lateral position. We determined the frequency of contractions. A positive test was considered when there were four or more contractions per hour before the 30th week of gestation and from 30 weeks onward, 6 or more contractions per hour. All pregnant women were asked for symptoms of preterm labor like heaviness, cramps, abdominal colics, and sudden gush of fluid.

\section{Statistical analysis:}

Recorded data were analyzed using the statistical package for the social sciences, version 20.0 (SPSS Inc., Chicago, Illinois, USA). Quantitative data were expressed as mean \pm standard deviation (SD). Qualitative data were expressed as frequency and percentage. The following tests were done: Independent-samples ttest of significance was used when 
comparing between two means. Mann Whitney $U$ test for two-group comparisons in non-parametric data. Chisquare $\left(\chi^{2}\right)$ test of significance was used in order to compare proportions between qualitative parameters. The confidence interval was set to $95 \%$ and the margin of error accepted was set to $5 \%$. So, the pvalue was considered significant as the following: Probability (P-value); P-value $<0.05$ was considered significant.

\section{RESULTS}

No statistically significant difference between was found between both groups according to their demographic data (Table 1).

Table (1): Comparison between progesterone group and placebo group according to their demographic data

\begin{tabular}{|c|c|c|c|}
\hline Demographic data & $\begin{array}{c}\begin{array}{c}\text { Progesterone } \\
(n=105)\end{array} \\
\end{array}$ & $\begin{array}{c}\text { Placebo } \\
(n=52)\end{array}$ & p-value \\
\hline \multicolumn{4}{|l|}{ Age (years) } \\
\hline Mean \pm SD & $27.83 \pm 3.26$ & $28.35 \pm 3.15$ & \multirow{2}{*}{0.343} \\
\hline Range & $21-35$ & $21-34$ & \\
\hline \multicolumn{4}{|l|}{ Parity } \\
\hline Median (IQR) & $2(1)$ & $2(1)$ & \multirow{2}{*}{0.813} \\
\hline Range & 1 & $1-4$ & \\
\hline \multicolumn{4}{|c|}{ Previous preterm labor } \\
\hline Median (IQR) & $1(2)$ & $2(1)$ & \multirow{2}{*}{0.265} \\
\hline Range & $1-3$ & $1-3$ & \\
\hline \multicolumn{4}{|l|}{ BMI [wt/(ht)^2] } \\
\hline Mean \pm SD & $25.31 \pm 3.26$ & $24.36 \pm 3.42$ & \multirow{2}{*}{0.093} \\
\hline Range & $20.1-31.7$ & $20.2-33.9$ & \\
\hline
\end{tabular}

There was a statistically significant difference between both groups as regards the presence of preterm labor with higher percentage of preterm labor $<36$ weeks among placebo $(38.5 \%)$ compared to progesterone cases $(21 \%)$, and there was statistically significant difference between both groups as regards the presence of early preterm labor with higher percentage of early preterm labor (before 34 weeks) in Placebo group $21.2 \%$ compared to $5.7 \%$ in progesterone group, and there was statistically significant difference between both groups as regard the mean gestational age at delivery $(37.57 \pm 1.72)$ wks higher in progesterone group compared to placebo group $(36.36 \pm 2.83)$ wks, but no statistically significant difference was found between both groups according to their working status (Table 2). 
Table (2): Comparison between progesterone group and placebo group according to their presence of preterm labor $(<36$ weeks), the mean gestational age at delivery, presence of early preterm labor ( $<34$ weeks) and working status

\begin{tabular}{|c|c|c|c|}
\hline Presence of preterm labor & $\begin{array}{c}\text { Progesterone } \\
(n=105)\end{array}$ & $\begin{array}{c}\text { Placebo } \\
(\mathrm{n}=52)\end{array}$ & p-value \\
\hline$<36$ weeks & $22(21.0 \%)$ & $20(38.5 \%)$ & \multirow{2}{*}{0.032} \\
\hline$\geq 36$ weeks & $83(79.0 \%)$ & $32(61.5 \%)$ & \\
\hline \multicolumn{4}{|c|}{ Presence of early preterm labor } \\
\hline$<34$ weeks & $6(5.7 \%)$ & $11(21.2 \%)$ & \multirow{2}{*}{0.008} \\
\hline$\geq 34$ weeks & $99(94.3 \%)$ & $41(78.8 \%)$ & \\
\hline \multicolumn{4}{|l|}{ GA (wks) at delivery } \\
\hline Mean \pm SD & $37.57 \pm 1.72$ & $36.36 \pm 2.83$ & 0.002 \\
\hline \multicolumn{4}{|l|}{ Working status } \\
\hline Working & $38(36.2 \%)$ & $23(44.2 \%)$ & \multirow{2}{*}{0.424} \\
\hline Housewife & $67(63.8 \%)$ & $29(55.8 \%)$ & \\
\hline
\end{tabular}

There was a statistically significant difference between both groups as regards the presence of symptoms of preterm labor with higher percentage $75 \%$ in placebo group compared to $52.4 \%$ in progesterone group, and there was statistically significant difference between both groups as regards the presence of uterine contractions with higher percentage $(48.1 \%)$ in placebo group compared to $(24.8 \%)$ in progesterone group, but no statistically significant difference was found between both groups as regards the mean gestational age at delivery in preterm neonates (Table 3).

Table (3): Comparison between progesterone group and placebo group according to their presence of symptoms of preterm labor, presence of uterine contractions using external Tocodynamometer and their mean gestational age at delivery in preterm neonates ( $<36$ weeks)

\begin{tabular}{|c|c|c|c|}
\hline $\begin{array}{l}\text { Presence of uterine contractions } \\
\text { using external tocodynamometer }\end{array}$ & $\begin{array}{c}\text { Progesterone } \\
(n=105)\end{array}$ & $\begin{array}{c}\text { Placebo } \\
(\mathrm{n}=52)\end{array}$ & p-value \\
\hline With uterine contractions & $26(24.8 \%)$ & $25(48.1 \%)$ & \multirow{2}{*}{0.006} \\
\hline Without uterine contractions & $79(75.2 \%)$ & $27(51.9 \%)$ & \\
\hline \multicolumn{4}{|l|}{ Presence of symptoms of preterm labor } \\
\hline Symptomatic & $55(52.4 \%)$ & $39(75.0 \%)$ & \multirow{2}{*}{0.011} \\
\hline Asymptomatic & $50(47.6 \%)$ & $13(25.0 \%)$ & \\
\hline \multicolumn{4}{|l|}{ GA (wks) at delivery } \\
\hline Mean \pm SD & $34.14 \pm 1.81$ & $32.93 \pm 2.12$ & 0.053 \\
\hline
\end{tabular}

\section{DISCUSSION}

As regarding to demographic data (age, parity, body mass index, and number of previous preterm labor and occupation of the mothers) there were no statistically significant differences between both groups.
As regard the presence of preterm labor before completing 36 weeks, there was a statistically significant difference between both groups. In the current study, the incidence of preterm delivery in the progesterone group was $21 \%(22 / 112)$ less than in the placebo group 38\% (20/56). 
This agreed with Fazzi et al. (2017) who reported that the incidence of preterm labor was $13.8 \%$ in progesterone group compared with $28.5 \%$ in placebo group and the difference was statistically significant. Our results were consistent with Othman (2020) who reported that the incidence of preterm labor birth was $29.4 \%$ in progesterone group compared with $45.1 \%$ in placebo group and the difference was statistically significant.

As regard the incidence of early preterm labor $(<34$ weeks) there was a statistically significant difference between both groups. The incidence of early preterm birth in progesterone group was $5.7 \%$ compared to $21.2 \%$ in placebo group. This agreed with Fazzi et al. (2017) where the incidence of delivery before 34 weeks of gestation was $2.8 \%$ in progesterone group compared with $18.6 \%$ in the placebo group and the difference was statistically significant.

As regard the mean gestational age at delivery, there was a statistically significant difference between both groups. The gestational age at delivery was lower in placebo group (mean $36.36 \pm$ 2.83 weeks) compared to progesterone group (mean $37.57 \pm 1.72$ weeks). These findings were supported by Fazzi et al. (2017) who reported that mean gestational age at delivery in progesterone group (37 \pm $2.8)$ weeks versus $(36 \pm 3.3)$ weeks in placebo group.

As regard the presence of symptoms of preterm labor, there was a statistically significant difference between both groups. Fewer women in progesterone group reported symptoms of preterm labor $52 \%$ compared with $75 \%$ in placebo group. Contradictory results to our data have been reported by Othman et al. (2020) who found that patient selfassessment of symptoms of preterm labor was not predictor of preterm labor, and there was no significant difference between daily and weekly contact with the patients about symptoms of preterm labor as regards incidence of preterm labor. Another contradictory result to our data have been reported by Pustotina (2018) where no significant difference between daily and weekly contact with the patients about symptoms of preterm labor in progesterone group $66.2 \%$ compared to $74 \%$ in placebo group.

As regard to presence of uterine contractions using external tocodynamometer, there was a statistically significant difference between both groups. The frequency of uterine contractions of more than four contractions per hour was more frequently found in the placebo group (48.5\%) than in the progesterone group (25\%), and the difference was statistically significant. which were supported by the results reported by Fazzi et al. (2017) where uterine contractions as more frequently found among placebo group than in the progesterone group (54.3\% Vs $23.6 \%$ ) respectively.this could be due to the differensce in dosages

\section{CONCLUSION}

Prophylactic vaginal progesterone reduced the rate of preterm labor, prolonged gestational age at delivery, reduced the frequency of uterine contractions, and improved the symptoms of preterm labor in women with previous history of preterm labor. 


\section{REFERENCES}

1. ACOG (2018): Practice bulletin no. 95 Anemia in pregnancy. Obstet Gynecol., 112 (1): 201-7.

2. Delnord M, Blondel B and Zeitlin J. (2015): What contributes to disparities in the preterm birth rate in European countries?. Current Opinion in Obstetrics \& Gynecology, 27(2):42133.

3. Fazzi C, Saunders DH, Linton K, Norman JE and Reynolds RM. (2017): Sedentary behaviours during pregnancy: a systematic review. International Journal of Behavioral Nutrition and Physical Activity,14(1):32-113.

4. Iams JD and Berghella V. (2010): Care for women with prior preterm birth. American Journal of Obstetrics and Gynecology, 203(2):89-100.

5. Kota SK, Gayatri K, Jammula S, Kota SK, Krishna SV, Meher LK and Modi KD. (2013): Endocrinology of parturition. Indian Journal of Endocrinology and Metabolism, 17(1):9-50.
6. Micks E, Raglan GB and Schulkin J. (2015): Bridging progestogens in pregnancy and pregnancy prevention. Endocrine Connections, 4(4): R81-92.

7. Othman AA. (2020): The Value of Oral Micronized Progesterone in the Prevention of Spontaneous Preterm Birth: A Randomized Control Trial (Doctoral dissertation). Acta Obstet Gynecol Scand,99(3)427-428

8. Pustotina O. (2018): Effectiveness of dydrogestrone, 17-OH progesterone in prevention of preterm birth in women with short cervix. The journal of Maternal-Fetal \&Neonatal Taylor\& Francis-Medicine, 31(14):1830-1838.

9. Rundell K and Panchal B. (2017): Preterm Labor: Prevention and Management. American Family Physician, 95(6):366-372.

10.Suman V and Luther EE. (2020): Preterm labor. In: StatPearls [Internet]. 2020 Jan 14. Treasure Island (FL), Pbl StatPearls Publishing:.

11. Wagura PM. (2014): Prevalence and factors associated with preterm birth at Kenyatta National Hospital (Doctoral dissertation, Thesis). University of Nairobi, 18(1):107. 


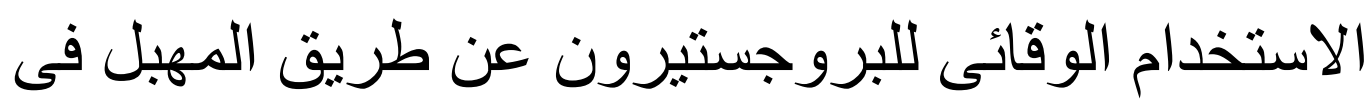

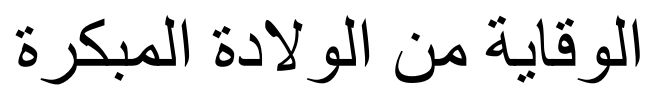

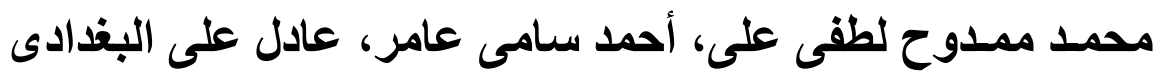

قسم التوليد وأمراض النساء، كلية الطب، جامعة الأزهر

E-mail: mam64156@gmail.com

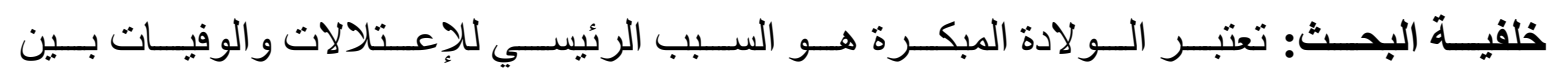

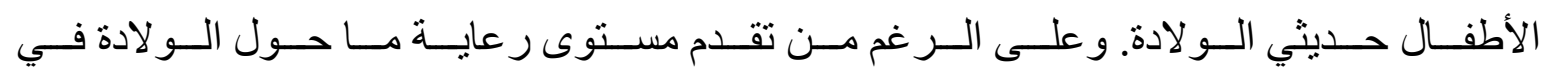

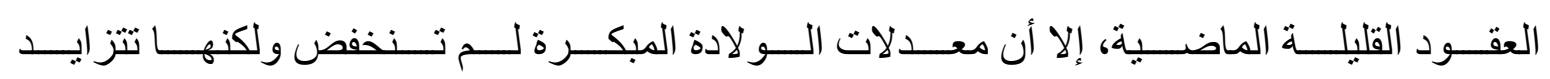
وتخلق مشكلة اجتماعية و اقتصادية كبيرة.

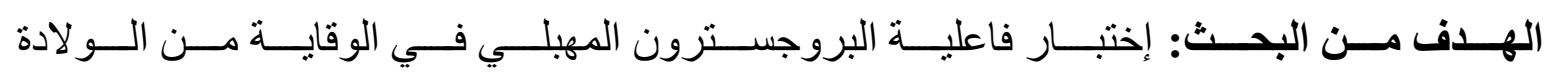
المبكرة لاى المريضات اللاتى لديهن تاريخ سابق للو لادة المباعة المبكرة.

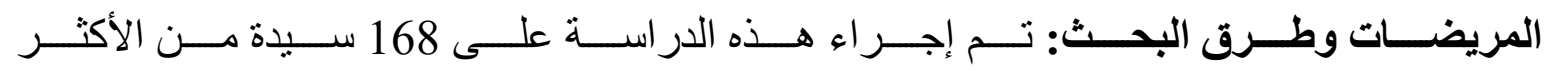

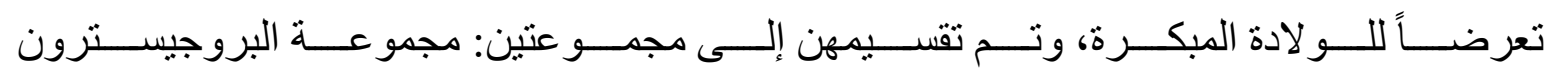

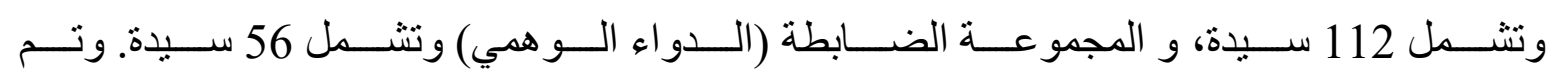

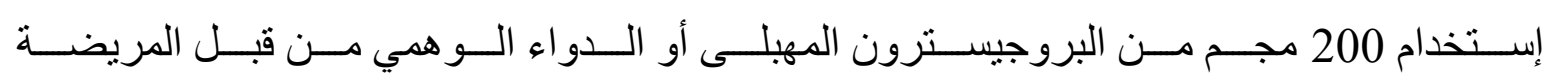

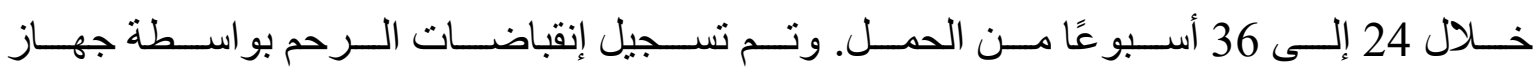

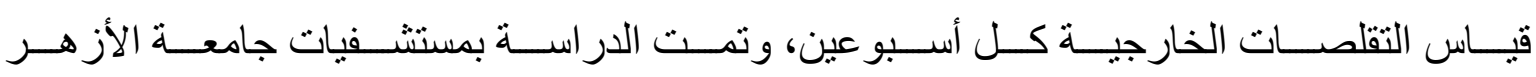

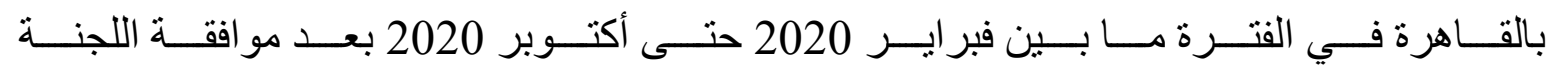

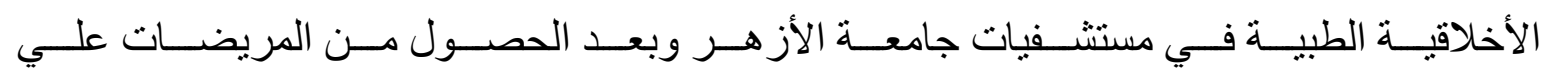
مو افقات كتابية.

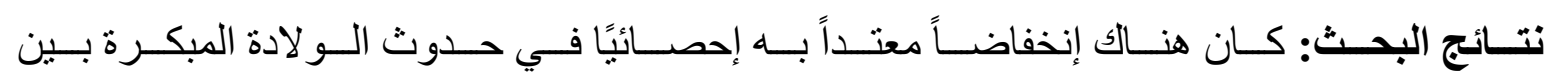

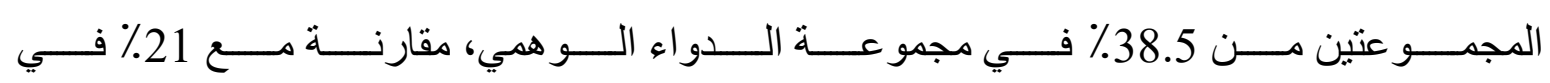

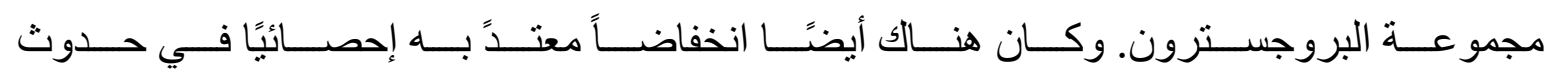

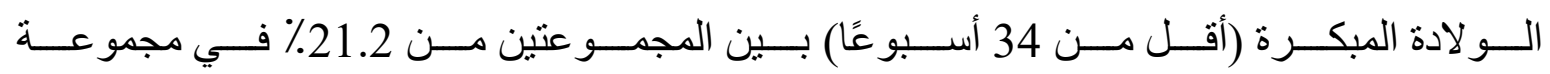

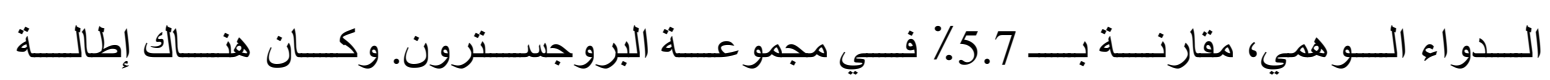

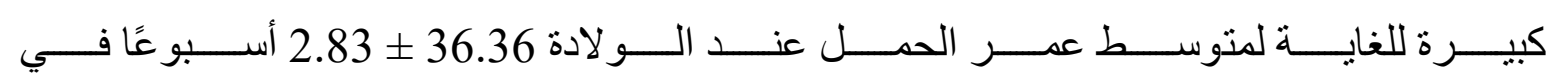




\section{PROPHYLACTIC USE OF PROGESTERONE VAGINAL...}

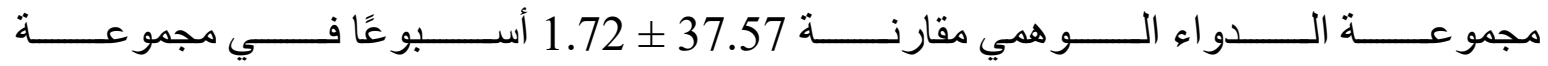

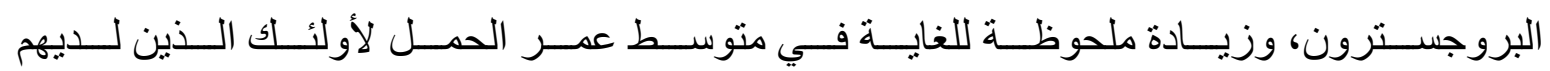

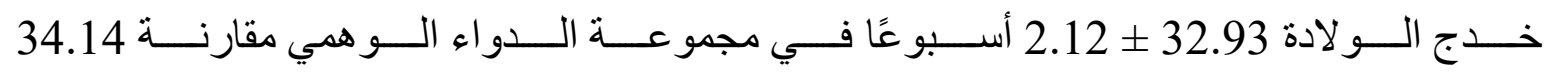

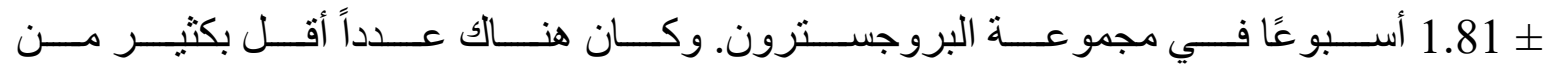

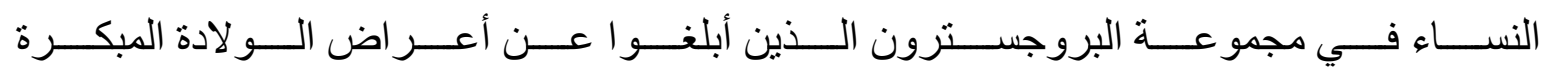

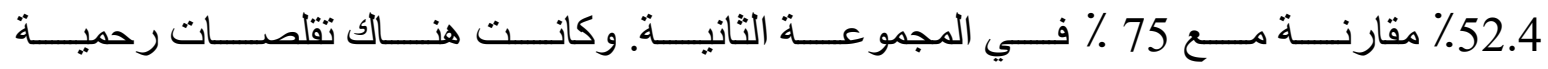

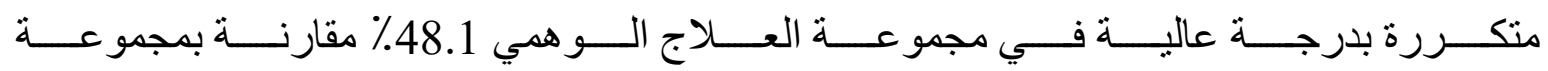
البروجسترون 24.8\%.

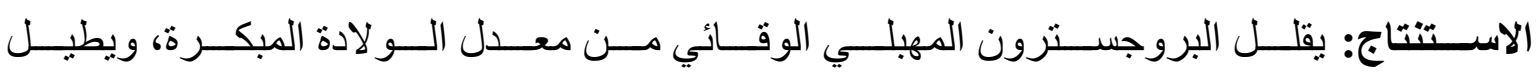

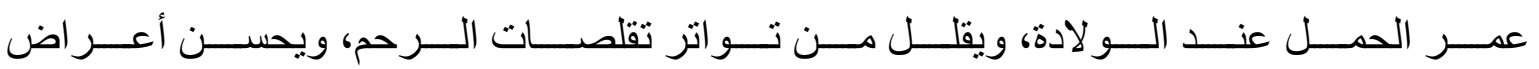
المخاض المبكر عند النساء المعرضات لخطر الولادة المبكرة.

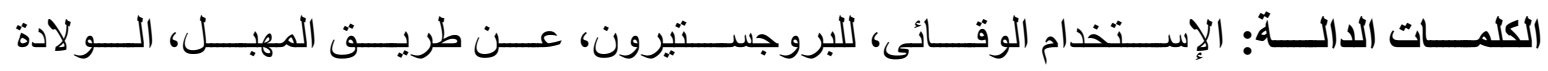
المبكرة. 